\title{
Comparison of real-time contrast-enhanced ultrasonography and standard ultrasonography in liver cancer microwave ablation
}

\author{
SHI-YAN YAN*, YI ZHANG* , CHAO SUN, HAI-XIA CAO, GUANG-MING LI, \\ YU-QIN WANG and JIAN-GAO FAN \\ Department of Gastroenterology, Xinhua Hospital, Shanghai Jiaotong University School of Medicine, \\ Shanghai 200092, P.R. China
}

Received April 27, 2016; Accepted June 10, 2016

DOI: $10.3892 /$ etm.2016.3448

\begin{abstract}
Primary liver cancer has a high incidence and high mortality rates, and currently the only viable option is surgery, although there are a number of difficulties related to this method. The aim of the present study was to investigate the potential advantages of the real-time contrast-enhanced ultrasonography (CEUS) for microwave ablation of primary liver cancer. One hundred patients with primary liver cancer were included in the study. The patients were divided into the ordinary ultrasonography and the CEUS groups. For the ordinary ultrasonography group, the ordinary ultrasonography-guided microwave ablation method was used, while microwave ablation under the guidance of CEUS was conducted for the CEUS group. The size of lesions and clearness of the tumor boundary prior to surgery in the two groups were compared. Additionally, postoperative complications and the survival rate were monitored. Lesion boundary areas measured by CEUS were significantly larger than those measured with ordinary ultrasonography. The incidence rate of postoperative pain, fever, intra-abdominal hemorrhage and infection and other complications in the ordinary ultrasonography group were significantly higher than that in the CEUS group. The tumor recurrence rate in the CEUS group was significantly lower than that in the ordinary ultrasonography group. Seventy-two percent of patients in the CEUS group showed no progress, compared to $48 \%$ of in the ordinary ultrasonography group. The progress-free survival rate in the CEUS group after 6 months was significantly higher than that in the ordinary ultrasonography group. Disease-free survival
\end{abstract}

Correspondence to: Dr Yu-Qin Wang or Dr Jian-Gao Fan, Department of Gastroenterology, Xinhua Hospital, Shanghai Jiaotong University School of Medicine, 1665 Kongjiang Road, Shanghai 200092, P.R. China

E-mail: yu_qinwang1@163.com

E-mail: jian_gaofan1@163.com

*Contributed equally

Key words: contrast-enhanced ultrasonography, primary liver cancer, microwave ablation time in the CEUS group was considerably longer than the control group. In conclusion, the guidance of real-time CEUS on the primary liver cancer microwave ablation treatment can achieve good intra-operative results. It offers a real-time guidance effect, improves survival time and reduces the incidence of complications.

\section{Introduction}

Primary liver cancer has an incidence of up to 250,000 new cases annually and high mortality rates, with a five-year survival rate of only $5 \%$ (1). Men were diagnosed more often than women (5:1). Men over 40 and women over 60 are the most affected population (1). Surgical resection is the main method of treatment for liver cancer, but there are several difficulties associated with this method (1). The advent of the microwave ablation, which is a minimally invasive treatment, provided new hope for liver cancer patients (2). There are a number of advantages associated with this type of treatment, including higher thermal efficiency, rapid warming and thorough solidification zone of necrotic tumor cells.

Contrast-enhanced ultrasonography (CEUS) can be used to observe the tumor treatment process, tumor blood perfusion and vascular condition and provide valuable information (3) for the qualitative diagnosis and treatment of cancer.

In the present study, we investigated the possible advantages associated with the use of real-time CEUS in the primary liver cancer microwave ablation treatment and obtained favorable results.

\section{Materials and methods}

General information. From January, 2010 to September, 2012, 100 patients diagnosed with primary liver cancer were enrolled in this study. A total of 116 lesions in these patients were examined. There were 54 men and 46 women, aged 39-74 years (mean age, 61.2 \pm 1.7 years). According to liver function Child-Pugh grading there were 70 cases in grade A and 30 cases in grade B. Tumor diameters were $\leq 3 \mathrm{~cm}$ and the platelet count was $>30 \times 10^{9} / 1$. The patients enrolled in this study were treated for the first time, in line with the liver cancer microwave ablation treatment scheme after multidisciplinary consultation. 
Exclusion criteria for the study were: Patients in grade $\mathrm{C}$ (Child-Pugh grading), patients with serious heart, lung or vital organ problems, patients with coagulation disorder or platelet count of $<30 \times 10^{9} / 1$ and cases with lesions at common hepatic duct and hepatic portal with a size of $<0.5 \mathrm{~cm}$. The patients were divided into the ordinary ultrasonography and CEUS groups with 50 patients in each group, and 58 lesions in each group. Comparison of the general patient information (ages, Child-Pugh grading, tumor size and platelet counts) in the two groups showed no statistical difference $(\mathrm{P}>0.05)$.

Methods. A color Doppler ultrasound diagnostic instrument was used in the ordinary ultrasonography group and the section under the lesion vision was selected and recorded. Microwave ablation (Youxi Scientific instrument co., LTD, Guangzhou, China) was then implemented with RF microwave equipment in the CEUS group, based on the implementation of routine ultrasonic examinations of lesion tissues. Microwave ablation was implemented under the guidance of CEUS. During real-time CEUS, the right amount of contrast agent (SonoVue, Bracco, Milan, Italy) was injected and then allocation and contrast intensity of the contrast agent were verified. Location and the size of the lesion were determined and the radiofrequency microwave equipment was used for ablation treatment. Tumors with larger diameters were ablated with a multi-needle surgical electrode and the tumors with special lesion sites and smaller diameter were ablated with a single needle surgical electrode. Microwave temperature was controlled at $90^{\circ} \mathrm{C}$ and the ablation time was $\sim 20 \mathrm{~min}$. After $\sim 5$ min into the surgery, the CEUS examination was implemented again to closely detect any enhanced signal indicating incomplete tumor inactivation and the need for a second intervention.

Efficacy evaluation. After one month of treatment, all the cases underwent enhanced computed tomography, $\alpha$-fetoprotein (AFP) and other examinations. Details of each follow up were recorded and if the patients had new lesions other than primary lesions during follow-up or AFP elevation, the cases were recorded as recurrence after treatment (4). Subsequently, the long-term progress-free survival time in the two groups was compared.

Statistical analysis. SPSS 21.0 software (Chicago, IL, USA) was used for statistical analysis. Countable data were tested using the $\chi^{2}$ test and the measurement data using the t-test. The survival curve was drawn according to the disease progress-free survival time after the first microwave radiofrequency, and the log-rank test was applied to compare the differences in progress-free survival time. $\mathrm{P}<0.05$ was considered to indicate a statistically significant difference.

\section{Results}

Preoperative clearness and size of lesion boundaries. Of the 58 lesions included in the CEUS group, the average diameter of lesions examined with ordinary ultrasonography prior to the implementation of CEUS was $2.32 \pm 0.44 \mathrm{~cm}$. By evaluating the lesions after the implementation of CEUS, it was found that $37 / 58$ lesions (63.8\%) were enlarged and the average diameter
Table I. Comparison of maximum diameters and areas of the lesions examined by ordinary ultrasonography and CEUS before the implementation of microwave ablation on 58 lesions in the CEUS group.

\begin{tabular}{lcc}
\hline $\begin{array}{l}\text { Examination } \\
\text { method }\end{array}$ & $\begin{array}{c}\text { Maximum diameter } \\
\text { of the lesion }(\mathrm{cm})\end{array}$ & $\begin{array}{c}\text { Maximum area } \\
\text { of the lesion }\left(\mathrm{cm}^{2}\right)\end{array}$ \\
\hline $\begin{array}{l}\text { Ordinary } \\
\text { ultrasonography }\end{array}$ & $2.32 \pm 0.44$ & $6.1 \pm 2.5$ \\
CEUS & $2.65 \pm 0.32^{\mathrm{a}}$ & $7.2 \pm 3.3^{\mathrm{a}}$ \\
\hline
\end{tabular}

Compared with the ordinary ultrasonography, ${ }^{\mathrm{a}} \mathrm{P}<0.05$. CEUS, contrast-enhanced ultrasonography.

Table II. Comparison of postoperative complications between the two groups, $\mathrm{n}(\%)$.

\begin{tabular}{|c|c|c|c|c|c|}
\hline Groups & $\mathrm{n}$ & Pain & Fever & $\begin{array}{l}\text { Intra-abdominal } \\
\text { hemorrhage }\end{array}$ & Infection \\
\hline $\begin{array}{l}\text { Ordinary } \\
\text { ultrasonography }\end{array}$ & 50 & $27(54)$ & $21(42)$ & $8(16)$ & $12(24)$ \\
\hline CEUS & 50 & $14(28)^{a}$ & $14(28)^{\mathrm{a}}$ & $3(6)^{\mathrm{a}}$ & $2(4)^{\mathrm{a}}$ \\
\hline
\end{tabular}

Compared with ordinary ultrasonography group, ${ }^{\mathrm{a}} \mathrm{P}<0.05$. CEUS, contrast-enhanced ultrasonography.

of the lesion was $2.65 \pm 0.32 \mathrm{~cm}$. The boundary areas of the lesion detected by CEUS was larger than those detected using ordinary ultrasonography $(\mathrm{P}<0.05)$ (Table I).

Postoperative complications. The incidence rate of postoperative pain, fever, intra-abdominal hemorrhage, infection and other complications in patients in the ordinary ultrasonography group was significantly greater that those in the CEUS group $(\mathrm{P}<0.05)$ (Table II).

Tumor recurrence. During the follow-ups, in the CEUS group, we observed a tumor recurrence rate equal to $16 \%$, which was significantly lower than the $48 \%$ found in the ordinary ultrasonography group. The difference was statistically significant $(\mathrm{P}<0.05)$ (Table III). The recurrent cases in the CEUS group showed abnormal enhancement inside the ablated lesions during the arterial phase or peripheral abnormal enhancement (Fig. 1).

Long-term progress-free survivals. We had 72 and $48 \%$ of progress-free patients in the CEUS and ordinary ultrasonography groups, respectively. The progress-free survival rate in the CEUS group after 6 months was $70 \%$, which was higher than that of the ordinary ultrasonography group (44\%). The median survival time in the ordinary ultrasonography group was 11.7 months, while the CEUS group did not reach the median survival time. Disease progress-free survival time in the CEUS group was longer than that of the ordinary ultrasonography group $(\mathrm{P}<0.05)$ (Fig. 2). 
Table III. Comparison of tumor recurrence rates in the two groups.

\begin{tabular}{|c|c|c|c|c|c|}
\hline Groups & $\mathrm{n}$ & $\begin{array}{l}\text { Local } \\
\text { recurrence }\end{array}$ & $\begin{array}{l}\text { Distant } \\
\text { recurrence }\end{array}$ & $\begin{array}{c}\text { Combination } \\
\text { (local/distant recurrence) }\end{array}$ & $\begin{array}{l}\text { Recurrence } \\
\text { rate }(\%)\end{array}$ \\
\hline Ordinary ultrasonography & 50 & 8 & 11 & 5 & 48 \\
\hline CEUS & 50 & 4 & 3 & 1 & $16^{\mathrm{a}}$ \\
\hline
\end{tabular}

Compared with ordinary ultrasonography group, ${ }^{\mathrm{a}} \mathrm{P}<0.05$. CEUS, contrast-enhanced ultrasonography.

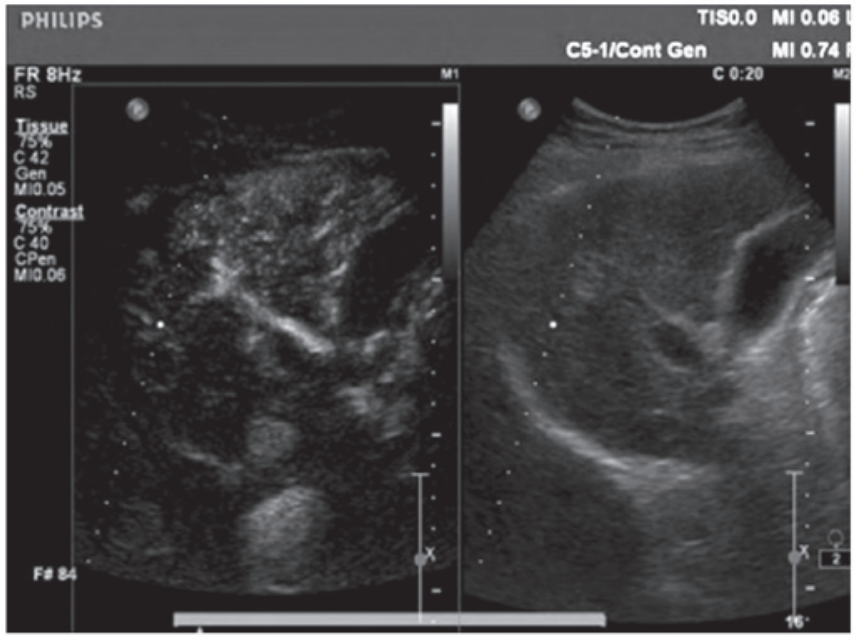

Figure 1. There was no echo nodule near the diaphragm at the right posterior lobe of the liver after the microwave ablation of primary liver cancer (right). The CEUS group during the arterial phase showed rapid overall enhancement (left). CEUS, contrast-enhanced ultrasonography.

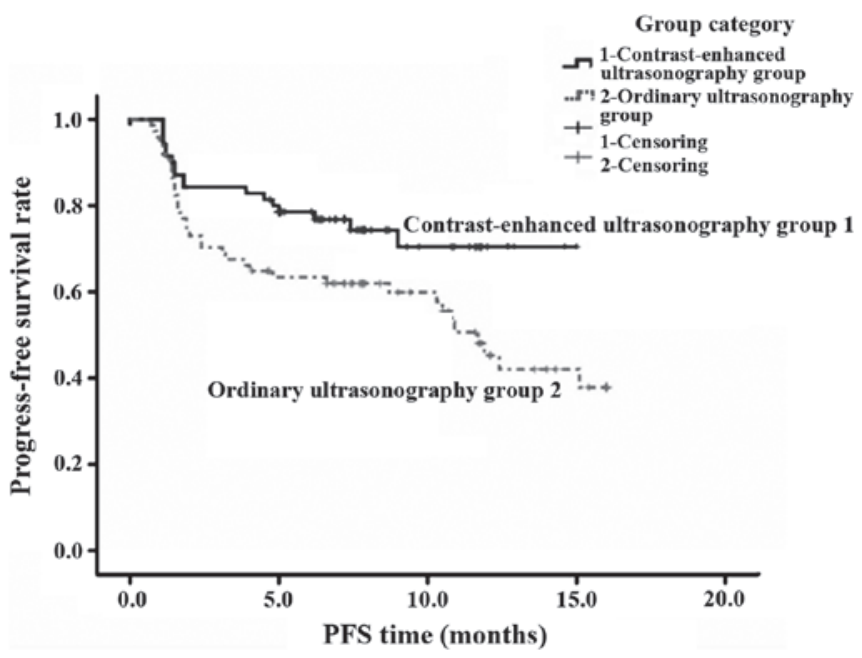

Figure 2. Comparison of long-term progress-free survival rate after microwave ablation between the two groups. CEUS, contrast-enhanced ultrasonography.

\section{Discussion}

Locating the tumor boundaries and defining the size and the number of lesions are key elements in treating liver cancer. The range of microwave ablation is generally from 0.5 to $1.0 \mathrm{~cm}$ more than the lesion tissue boundary (5-8), therefore the safe 'no tumor edge' $(9,10)$ can be ensured and the residual tumor lesion can be reduced. When examining tumors with different morphologies and unclear boundaries, the ordinary ultrasonography is prone to measurement errors (11-14). Our results showed that the boundary area of lesions detected by CEUS was larger than that of the ordinary ultrasonography, which suggested that CEUS may better reflect the characteristics of the lesions. Our results also revealed that the measurement value of CEUS was greater than that of the ordinary ultrasonography. CEUS also created a better contrast between the tumor and surrounding tissues, which is good for an accurate detection of lesions. Microwave ablation is influenced by the tumor's blood supply and if tumors are close to large vessels and the blood supply is richer. This affects the heat transfer and thereby influences the outcome of the microwave ablation (15-17). CEUS can accurately identify the location of feeding vessels and effectively enhance the tumor microwave ablation inactivation rate. Our results showed that the tumor recurrence rate in the CEUS group was significantly lower than the rate observed in the ordinary ultrasonography group.

Microwave ablation under the guidance of CEUS could effectively prevent tumor lesion survival and recurrence rate and improve disease-free survival time of patients. The incidence rate of postoperative pain, fever, intra-abdominal hemorrhage, infection and other complications of patients in the ordinary ultrasonography group were significantly higher than the complication incidence rate of the patients in the CEUS group. Our results suggested that the implementation of the microwave ablation under the guidance of CEUS reduced the incidence of adverse reactions, such as pain, fever and other minor complications. Fever is a common reaction to microwave ablation because in this situation apoptotic pathways are triggered and high levels of inflammatory mediators are released into the bloodstream (18). Source of pain in patients may be the liver capsule tension, coagulation, necrosis, hyperemia and edema. Pain is usually exacerbated in the cases where tumor is near the lower part of the diaphragm or the liver capsule. The abovementioned complications may be relieved with symptomatic treatment. Previous studies reported that $(19,20)$ microwave ablation may induce serious life-threatening complications such as hemorrhage and bile fistula. However, in our study we did not encounter any of these complications.

In conclusion, the guidance of the real-time CEUS during the microwave ablation treatment of primary liver cancer achieved great intra-operative results. This method had the capability of providing us with clearer information regarding the size of the lesion and guided us to identify the best insertion 
point for the microwave ablation needle. Therefore, real-time CEUS improved the patient survival rate and reduced the risk of possible complications, and is worth being applied and promoted.

\section{Acknowledgements}

The present study was supported by the National Natural Science Foundation of China (nos. 81071888, 81070344, 81000173, 81070322 and 81270491), the National Key Basic Research Project (no. 2012CB517501), the 100-Talents Program of the Shanghai Municipal Health Bureau (no. XBR2011007), the Cross Research Fund of Shanghai Jiaotong University Biomedical Engineering (no. YG2012MS37), the Shanghai Natural Science Foundation (no. 13ZR1426700), and the Xinhua Hospital Clinical Research Project (no. 15LC16).

\section{References}

1. Kim AY, Lee MW, Rhim H, Cha DI, Choi D, Kim YS, Lim HK and Cho SW: Pretreatment evaluation with contrast-enhanced ultrasonography for percutaneous radiofrequency ablation of hepatocellular carcinomas with poor conspicuity on conventional ultrasonography. Korean J Radiol 14: 754-763, 2013.

2. Shah DR, Green S, Elliot A, McGahan JP and Khatri VP: Current oncologic applications of radiofrequency ablation therapies. World J Gastrointest Oncol 5: 71-80, 2013.

3. Mauri G, Cova L, De Beni S, Ierace T, Tondolo T, Cerri A, Goldberg SN and Solbiati L: Real-time US-CT/MRI image fusion for guidance of thermal ablation of liver tumors undetectable with US: results in 295 cases. Cardiovasc Intervent Radiol 38: 143-151, 2015.

4. Wolf FJ, Aswad B, Ng T and Dupuy DE: Intraoperative microwave ablation of pulmonary malignancies with tumor permittivity feedback control: ablation and resection study in 10 consecutive patients. Radiology 262: 353-360, 2012.

5. Nazem F, Ahmadian A, Seraj ND and Giti M: Two-stage point-based registration method between ultrasound and CT imaging of the liver based on ICP and unscented Kalman filter: a phantom study. Int J CARS 9: 39-48, 2014.

6. Bruix J and Sherman M; American Association for the Study of Liver Diseases: Management of hepatocellular carcinoma: an update. Hepatology 53: 1020-1022, 2011.

7. Sporea I, Badea R, Martie A, Dumitru E, Ioaniţescu S, Şirli R, Socaciu M, Popescu A, Dănilă M and Voiculescu M: Contrast Enhanced Ultrasound for the evaluation of focal liver lesions in daily practice. A multicentre study. Med Ultrason 14: 95-100, 2012.
8. Takahashi M, Maruyama H, Shimada T, Kamezaki H, Sekimoto T, Kanai F and Yokosuka O: Characterization of hepatic lesions $(\leq 30 \mathrm{~mm})$ with liver-specific contrast agents: a comparison between ultrasound and magnetic resonance imaging. Eur J Radiol 82: 75-84, 2013.

9. Sparchez Z,Radu P,Zaharia T, Kacso G, Grigorescu I, Botis G and Badea R: Usefulness of contrast enhanced ultrasound guidance in percutaneous biopsies of liver tumors. J Gastrointestin Liver Dis 20: 191-196, 2011

10. Zhang D, Liang P, Yu X, Cheng Z, Han Z, Yu J and Liu F: The value of artificial pleural effusion for percutaneous microwave ablation of liver tumour in the hepatic dome: a retrospective case-control study. Int J Hyperther 29: 663-670, 2013.

11. Widmann G, Schullian P, Haidu M and Bale R: Stereotactic radiofrequency ablation (SRFA) of liver lesions: technique effectiveness, safety, and interoperator performance. Cardiovasc Intervent Radiol 35: 570-580, 2012.

12. Mariani A, Kwiecinski W, Pernot M, Balvay D, Tanter M, Clement O, Cuenod CA and Zinzindohoue F: Real time shear waves elastography monitoring of thermal ablation: in vivo evaluation in pig livers. J Surg Res 188: 37-43, 2014.

13. Liu F, Liang P, Yu X, Lu T, Cheng Z, Lei C and Han Z: A three-dimensional visualisation preoperative treatment planning system in microwave ablation for liver cancer: a preliminary clinical application. Int J Hyperther 29: 671-677, 2013.

14. Wang XL, Li K, Su ZZ, Huang ZP, Wang P and Zheng RQ: Assessment of radiofrequency ablation margin by MRI-MRI image fusion in hepatocellular carcinoma. World J Gastroenterol 21: 5345-5351, 2015

15. Correa-Gallego C, Karkar AM, Monette S, Ezell PC, Jarnagin WR and Kingham TP: Intraoperative ultrasound and tissue elastography measurements do not predict the size of hepatic microwave ablations. Acad Radiol 21: 72-78, 2014.

16. Mauri G, Porazzi E, Cova L, Restelli U, Tondolo T, Bonfanti M, Cerri A, Ierace T, Croce D and Solbiati L: Intraprocedural contrast-enhanced ultrasound (CEUS) in liver percutaneous radiofrequency ablation: clinical impact and health technology assessment. Insights Imaging 5: 209-216, 2014.

17. Asvadi NH, Anvari A, Uppot RN, Thabet A, Zhu AX and Arellano RS: CT-guided percutaneous microwave ablation of tumors in the hepatic dome: assessment of efficacy and safety. J Vasc Interv Radiol 27: 496-502, 2016.

18. Zhang M, Liang P, Cheng ZG, Yu XL, Han ZY and Yu J: Efficacy and safety of artificial ascites in assisting percutaneous microwave ablation of hepatic tumours adjacent to the gastrointestinal tract. Int J Hyperther 30: 134-141, 2014.

19. Li M, Yu XL, Liang P, Liu F, Dong B and Zhou P: Percutaneous microwave ablation for liver cancer adjacent to the diaphragm. Int J Hyperther 28: 218-226, 2012.

20. Wu J, Yang W, Yin S, Wu J, Wu W, Yan K and Chen M: Role of contrast-enhanced ultrasonography in percutaneous radiofrequency ablation of liver metastases and efficacy evaluation. Chin J Cancer Res 25: 143-154, 2013. 